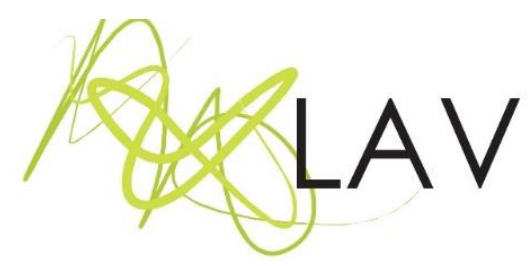

\title{
A potência edu(vo)cativa da arte contemporânea: desafios e possibilidades
}

\author{
The edu(vo)captive power of contemporary art: challenges and possibilities
}

Lutiere Dalla Vallei

Universidade Federal de Santa Maria

\section{Resumo}

Este texto explora a potencia edu(vo)cativa das artes como estratégia metodológica em ambiente escolar. Neste interim, parte-se de uma experiência de aprendizagem compartilhada a partir da exposição "A Translucidez do Corpo" inserida em uma escola de educação básica. Fazendo uso de metodologias interpretativas, buscou-se estabelecer relações de ensino-aprendizagem no campo das artes visuais sobre as três dimensões que constituem a abordagem edu(vo)cativa: educativa, evocativa e cativa. As ações dirigiramse sobretudo à educação infantil, investigando as relações entre arte, visualidade, imaginário e estudos anatômicos, conhecimentos relacionados ao corpo do ponto de vista da linguagem e da cultura. Como embasamento teórico-metodológico, nos respaldam autores e autoras que dialogam com a perspectiva educativa da cultura visual e pedagogias culturais.

Palavras-chave: educação, potencia edu(vo)cativa, arte contemporânea.

\begin{abstract}
This text explores the edu(vo)cative potential of the arts as a methodological strategy in the school environment. Meanwhile, we start with a shared learning experience from the exhibition "The Translucidity of the Body" inserted in a basic education school. Using interpretative methodologies, we sought to establish teaching-learning relationships in the field of visual arts on the three dimensions that constitute the edu(vo)cative approach: educational, evocative and captive. The actions were directed mainly to the primary education, investigating the relations between art, visuality, imaginary and anatomical studies, knowledge related to the body from the point of view of language and culture. As a theoretical-methodological basis, we are supported by authors who dialogue with the educational perspective of visual culture and cultural pedagogies.
\end{abstract}

Keywords: education, power edu(vo)captive, contemporary art. 


\section{Introdução}

No campo das artes visuais, seja em sua produção, difusão ou ensino, há constante movimentação acerca das múltiplas possibilidades de conceber os feitos culturais, o que demanda, igualmente, uma busca interminável por estratégias flexíveis, criativas e ativas dentro e fora dos centros de ensino. Diante das características contemporâneas que circundam o campo das artes - hibridas, relacionais, interativas, transacionais - bem como as relações entre ensino e aprendizagem, somos interpelados por uma profusão de possibilidades inventivas. Neste caso, nos implicamos com o ato de arquitetar e experimentar possíveis encontros com a arte e sua potência às múltiplas aprendizagens.

Enquanto proposição, a potencia edu(vo)cativa (DALLA VALLE, 2018) nos oferece algumas pistas para indagar juntamente com os/as estudantes as práticas discursivas e percepções ao incitar múltiplos questionamentos entorno aos objetos artísticos. A tríade justaposta: educativo, evocativo, cativo, sugere, portanto, a ideia de conectividade, de ajuntamento inclusivo, justificando-se pela experimentação a possibilidade de dar conta (ainda que provisoriamente) das experiências subjetivas e sensíveis com/a partir das artes sobretudo da arte contemporânea.

Longe de propor um método - muito menos de um caminho prescritivo - o interesse em explorar as potências edu(vo)cativas dos artefatos culturais, aqui podem ser tomados como pontos de partida que sinalizam caminhos e não linhas de chegada. Ou seja, ao propor uma abordagem edu(vo)cativa para as práticas artísticas/educativas, estaríamos lidando com perspectivas exploratórias/experimentais ao refletir acerca das questões culturais que incluem práticas de sentido, do olhar, especialmente de como construímos nossas relações com o mundo.

A partir de experiências que vimos realizando em um núcleo educativo e alguns projetos de extensão no ensino superior (vinculados ao Curso de Artes Visuais - Licenciatura em Artes Visuais da Universidade Federal de Santa Maria) juntamente à práticas educativas em escolas locais, temos nos deparado com significativas contribuições ao fazer uso desta perspectiva de trabalho. E é com base nestas experiências que este texto toma forma ao tecer reflexões sobre possíveis maneiras de abordar a arte com crianças em contextos formais de ensino. Todavia, enquanto tema de nossas pesquisas, a abordagem em questão tem movimentado algumas possibilidades relevantes ao campo - aspectos e contribuições que examinaremos neste texto - para além de um relato de práticas desenvolvidas em projetos de extensão e grupos de pesquisa. 
Nossas expectativas partiram do desejo de contribuir com a formação em artes visuais no âmbito das relações criativas e críticas, das práticas coletivas e colaborativas entorno de produções artísticas locais. Da mesma forma, a busca por alternativas pedagógicas que levassem em consideração a especificidade da área e da mesma maneira, as contribuições dos saberes interdisciplinares que poderiam ser articulados a partir de uma experiência estética dentro da escola.

\section{Da curiosidade pueril aos projetos de investigação e experimentação}

Nos aproximamos dos objetos artísticos (assim como imagens publicitárias, filmes, vídeos) enquanto artefatos evocativos, uma vez que estão atrelados às percepções que envolvem nossa memória, trazem à tona nossas referências visuais anteriores que nos possibilitam explorar novas conexões, em processo constante de reconfiguração, estabelecendo novas/outras relações ao movimentar nosso pensamento. Outrossim, como artefatos educativos mediante práticas de sentido e significação com as quais aprendemos a conceituar nosso entorno, forjando visões de mundo, ensinando-nos formas de ser e estar, em especial em cada contexto de nossas experiências diárias - privadas, coletivas, sociais, culturais. Além disso, é qualidade das imagens sua potência de sedução, que nos aprisiona, ou seja, nos cativa ao estabelecer relações com aspectos que caracterizam nossas emoções, sentimentos e sensações diante daquilo que vemos, reconhecemos (ou estranhamos) e que, em certa medida, nos afetam.

Neste sentido, a arte transcende o que é visto ou narrado, uma vez que mobiliza nossa subjetividade ao promover ações de captura, de sedução visual ou repulsa, oferecendonos elementos que possam fazer-nos transitar pela imprevisibilidade poética e inventiva próprias da experiência estética. Além da provocação impulsionada pela curiosidade diante dos artefatos apresentados (os objetos artísticos) - sob a ótica da potência edu(vo)cativa - podem contribuir para desnaturalizar a visão da arte como representação, apreensão técnica e/ou ilustrativa que ainda impera com grande força em muitas escolas de educação básica para ceder lugar a concepções inventivas, autorais e autônomas (como temos vivenciado).

Em nosso contexto local, tendo em vista algumas dificuldades de acesso a produções artísticas contemporâneas por parte da maioria das escolas da região, percebeu-se a necessidade de desenvolver projetos em que as obras pudessem estabelecer diálogos com a comunidade, deslocando-se por estes espaços, mobilizando não apenas o pensamento a partir das interlocuções, mas também intervindo nos ambientes ao preparar-se para receber as ações educativas.

Revista Digital do LAV - Santa Maria - vol. 12, n. 1, p. 82 - 95 - jan./abr. 2019 ISSN 1983 - 7348 http://dx.doi.org/10.5902/1983734837258 
Diante disso, as estratégias educativas/pedagógicas foram tecidas para cada contexto, partindo de planejamento flexível e aberto a mudanças tendo em vista as imprevisibilidades do trabalho com crianças - dos rumos que surgiram a cada encontro, das narrativas que configuraram cada experiência, do tempo volátil e suas surpresas. Além disso, de acordo com a especificidade das obras que poderiam ser levadas a cada espaço, estratégias didáticas de cunho experimental foram projetadas com o objetivo de promover práticas de interação entre acadêmicos em formação na licenciatura em artes visuais, professoras pedagogas das séries iniciais, crianças e demais pessoas envolvidas na escola.

Ao propor exposições itinerantes nas escolas, visitas guiadas, diálogos com artistas e oficinas, experimentamos dinâmicas variadas em cada contexto: adaptamos a disposição das obras, redimensionamos tempos de conversa, redescobrimos nossas perguntas, revisitamos conceitos e concepções, convivemos com êxitos em determinadas proposições e fracassos em outras. Nosso fio condutor começava pela percepção visual da materialidade: iniciando por aquilo que as imagens poderiam lembrar, conectar, evocar, capturar: "o que parecem, ou lembram?"; "que ideias elas evocam?"; "sobre o que nos fazem pensar?"; "o que nos ensinam?" "O que diz de mim?"; com ênfase naquilo que identificamos, que (re)conhecemos, que já sabemos e nomeamos em diálogo com o que ainda não sabemos: sobre o que poderia ser, a partir da particularidade do sujeito que olha.

Em alguns casos, tomamos como ponto de partida nossas práticas edu(vo)cativas, obras expostas no espaço que a escola oferecia, como uma espécie de "varal", fixadas por prendedores (obras de variados artistas, produzidas em papéis, tecidos, plásticos ou similares, desenhos, gravuras, bordados, colagens, etc.); ou então, seguindo a estrutura do "cubo branco" ocupando o espaço "nobre" da escola, destinado às atividades culturais, com exposições de um único artista. Cada contexto, remetendo-nos à adaptação e aos objetivos negociados com a professora regente e com dirigentes da escola.

Começamos definindo alguns aspectos que julgamos relevantes para nossa organização ao observar, interagir e estabelecer relações com os ambientes escolares. Em seguida, nos colocamos em diálogo com a comunidade educativa a partir das expectativas e percepções a fim de sistematizar pontos de contato e pontos de discrepância; e por fim, nos dedicaríamos a pensar sobre o que a experiência possibilitaria aprender. Em seguida, reflexionar sobre o que poderíamos elaborar a partir das imagens produzidas pelas crianças em analogia com as obras expostas. Por fim, indagar como esta experimentação poderia configurar-se edu(vo)cativa nestes espaços de diálogo transitório e efêmero ocupados pelas exposições. 
Envolveram-se, pesquisaram, perguntaram, surpreenderam-se com a visão microscópica nos aparatos tecnológicos, encantaram-se com o laboratório de ciências da escola, com as reproduções de órgãos em acrílico, com as imagens de corpos dissecados (de animais e humanos) fixados às paredes - visualidades desconhecidas até aquele momento. Perguntaram, inventaram pequenas narrativas, desenharam, verbalizaram suas emoções e experiências de contato com as representações oriundas dos livros de ciências confrontando-as com as criações do artista e suas próprias grafias no papel vegetal.

A ausência de qualquer tipo de pigmento, as ranhuras produzidas pelo decalque das pontas secas (canetas sem tinta, palitos de churrasco, clipes de arame) no papel vegetal sobre uma mesa levemente macia, possibilitaram também o toque sensível à textura do papel, à percepção dos pequenos relevos, dos deslizes nas pequenas fissuras, das relações entre opacidade e transparência como reveladoras de experimentações. Tagarelavam enquanto feriam o papel, grafando nomes, letras, vocábulos recém apreendidos durante o processo de alfabetização: pequenas narrativas impressas de suas percepções e fabulações.

A exposição "A Translucidez do Corpo" disposta no Salão de Atos de uma escola apresentava uma série de 15 desenhos produzidos por um artista local em que eram exploradas representações de corpos fragmentados. Este foi um de nossos dispositivos/disparadores que mais nos possibilitou o exercício da provocação. Como compilatórios de vísceras, estruturas maleáveis, fluidas, referências às vanitas, os desenhos apresentavam crânios humanos e animais, órgãos, ossos, e demais estruturas compositivas em meio a florais e ornamentos que remetiam a cerimoniais e ritos religiosos. Os desenhos, feitos com ponta seca sob papel vegetal por meio do decalque, recebiam inferências gráficas por meio da força motriz que o fez ceder sob uma tenra superfície, criando pequenos relevos, contrastes sutis que só poderiam ser visualizados a partir do contraste com o fundo escuro e/ou incidência de luz. 


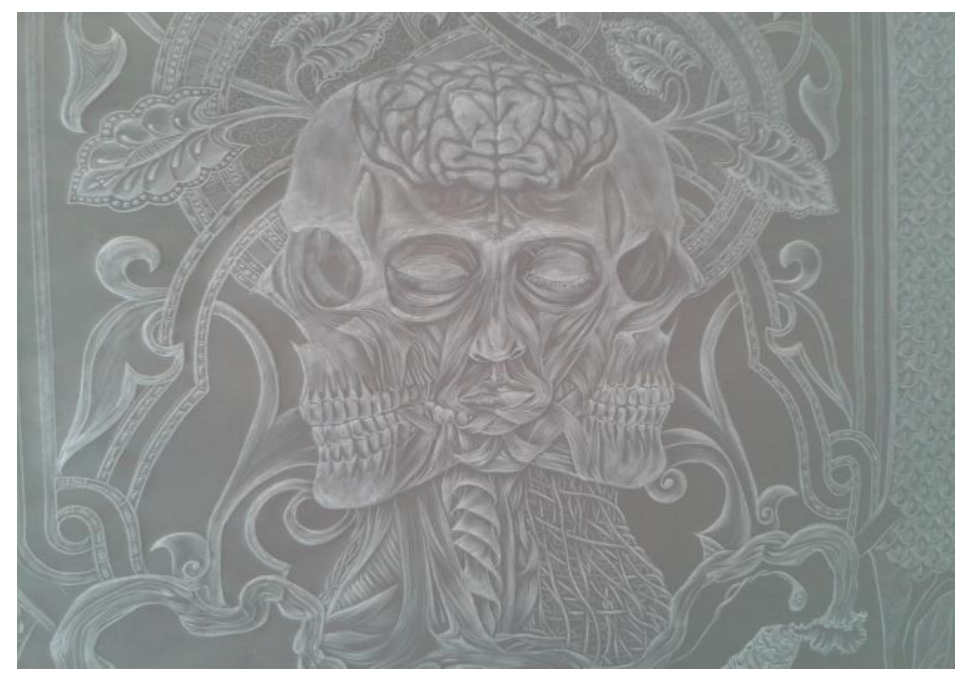

Figura 01. Detalhe do desenho em exposição "A "Translucidez do Corpo" papel vegetal em relevo. Santa Maria, RS, 2017.

Fonte: Arquivo Pessoal.

De imediato foi o interesse infantil pelas obras que suspensas por fios de nylon pareciam flutuar no espaço, movimentando-se sutilmente a partir dos pequenos corpos que circulavam entre si, provocando pequenos sopros no espaço. Suspendidas, possibilitaram a vista frente e verso, incitando-as ao deslocamento para relacionar o que poderia ser visto "à frente" e "atrás", explorando as relações entre o que pode ser visualizado/mostrado de distintas maneiras. Exploraram também a coloração instantânea dos desenhos ao utilizar folhas A4 coloridas colocando-as sob os desenhos para conseguir visualizar os pequenos detalhes e linhas impregnadas nos grandes suportes. Esta ação remetia à coloração artificial que devem sofrer os tecidos celulares sob as lâminas dos aparelhos microscópicos, pois, segundo nos explicava um professor de microscopia da universidade, "uma célula é translúcida até que seja colorida artificialmente: antes disso, nada se pode ver". Para o artista, este foi seu ponto de partida: explorar as relações de opacidade e transparência com as representações do corpo. Neste sentido, tomando por referência o argumento de Susana Rangel Vieira da Cunha, "O pensamento visual, imaginativo, processual das crianças tem muitos pontos de contato com os modos de os artistas contemporâneos produzirem arte" (CUNHA, 2017, p. 13). Além disso, segundo ela

O importante é oportunizar às crianças novas experiências e invenções com os materiais, sem delimitar em desenho, pintura, escultura, mas trabalhando com a hibridização das linguagens, fazendo 'desenhuras' $[\ldots]$, criando instalações de aromas, sons, sensações, extrapolando qualquer referência que temos sob a denominação de "artes visuais", indo além das linguagens tradicionais da arte (CUNHA, 2017, p. 18). 
Portanto, ao explorar outras possibilidades do desenho - enquanto ranhura, rasura, incisão - nosso intuito foi expandir as noções do que poderia significar o ato de desenhar. Pensar o desenho não apenas à maneira tradicional - o que preserva seu sentido - mas ampliar o repertório. Ou seja, experimentar com a linha, outras formas de elaboração, sobretudo pela ausência de algum tipo de pigmentação: um desenho sem cor, sem contraste. $O$ desenho através da sutileza do contato. O que poderia servir para esboçar, sistematizar, organizar, apreender uma relação formal de proporção, profundidade, interpretação e representação.

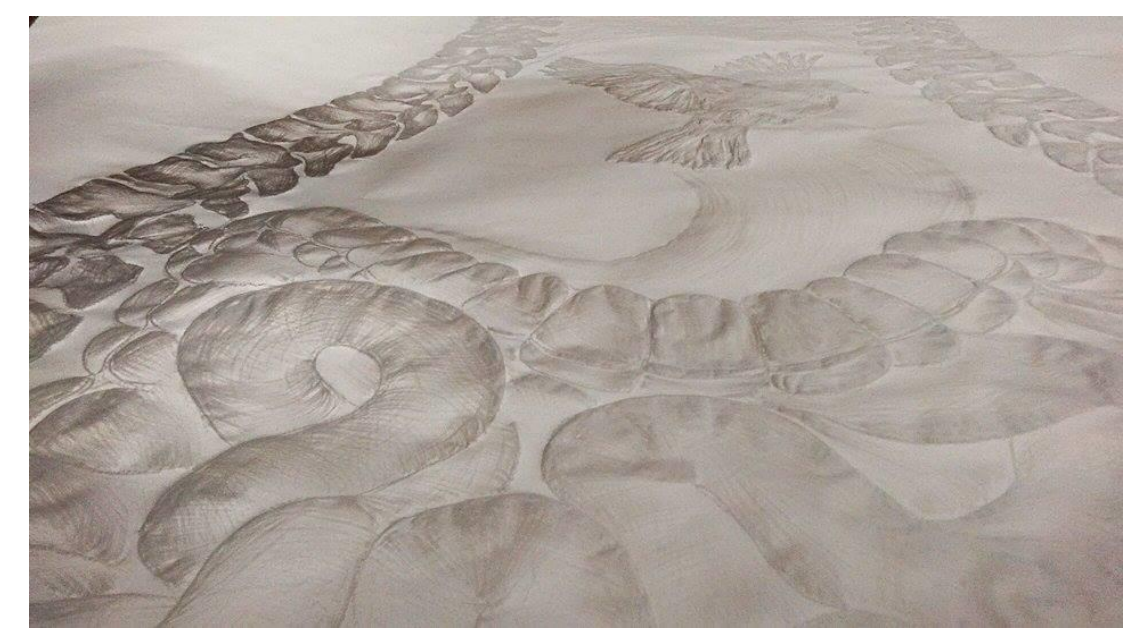

Figura 02. Detalhe do desenho em exposição "A Translucidez do Corpo" - papel vegetal em relevo. Santa Maria, RS, 2017.

Fonte: Arquivo Pessoal.

A partir desta experiência, tomamos o desenho sob o papel vegetal como início de um processo investigativo. Para os renascentistas, o desenho era projeto, esquema, esboço. Somente no início do século XX ganhou autonomia ao projetar-se livremente sem ser passagem. Foi (e ainda é) para muitos artistas, uma forma de anotar ideias que surgem tão rapidamente quanto desaparecem da memória e que, portanto, exigem alguma forma de apreensão esquemática. Neste sentido, encarado como registro rápido de insights, como método de construir mapas mentais das ideias. Inventamos o desenho para podermos dimensionar àquilo que nos escapa a outras formas de compreensão: o contorno sugerido pela grafia é próprio do nosso olhar, de nossa humanidade. Poderíamos arriscar que apenas compreendemos aquilo que conseguimos apreender a partir da síntese e do reconhecimento que se vincula à prática de estabelecer relações: uma coisa se conecta a outra, tecendo algumas redes de significado (que dentro de um contexto cultural ganha forma e sentido). "Desenhar, portanto, antes de ser uma capacidade de expressão, é um ato de consciência" (RESENDE, 2007, p. 59). 
Como um dos princípios de nosso desenvolvimento cognitivo e cultural, já na primeira infância fazemos interferências gráficas como forma de compreender e representar o universo simbólico que nos atravessa, como possibilidade de dar sentido à própria experiência de vida. Se pensarmos em nossa cognição processual, da mesma forma atribuímos às manifestações visuais/pictóricas dos homens e mulheres primitivos, o desejo de manifestar sua humanidade por meio do simbolismo criado a partir da observação da natureza. Somos animais simbólicos: nascemos dentro de um determinado espaço geográfico, mas ocupamos os lugares que a cultura nos oferece. Ou seja, mobilizados pela cultura passamos a construir maneiras de olhar e sermos vistos. Nas palavras de José Resende:

A capacidade de ver distingue qualidades, associa coisas e ideias, ordena sentidos hierarquizados pela escolha figura/fundo, gera consciência, portanto, sobre algo visto. Exercê-la é a função primeira do desenho. Visto desta forma, portanto, desenho é uma capacidade inata, ativa e sempre disponível desde que o sentido da visão se constitui, a qual não se pode delir (RESENDE, 2007, p. 59).

Neste sentido, o desenho participa do desenvolvimento cognitivo/mental: pois, "ver desenhos é conseguir captar, em certa medida, o processo criativo em ação" (SALLES, 2007 , p. 42). Ou seja, até certo ponto, o desenho reflete uma prática exploratória que continua à espera de materialização, como se estivesse, em um primeiro momento, atrelado essencialmente ao mundo das ideias. Entretanto, no contexto desta experiência, as noções de desenho com as quais compartilhamos não remetem apenas ao transitório ou esquemático, mas como resultado de um processo inventivo que não está na condição de materialização do pensamento: já o é. Fruto da confrontação de materiais diversos, de pesquisa visual, de experimentação material a partir das possibilidades que a compõem, tanto com relação ao gesto espontâneo quanto ao que constrói posteriormente por meio da linha.

Produzir artefatos visuais na forma de desenhos poderia atrelar-se a outros processos constitutivos com os quais nos enfrentamos cotidianamente: criar limites, delimitar áreas, estipular tempos de atuação. Igualmente, diluir linhas, desmantelar fronteiras, explorar áreas movediças. Limitar ou diluir, neste sentido, poderia incitar zonas de diálogo entre o que o produz e o que o torna objeto de observação: a invenção. Sobre nossas capacidades inventivas, nas palavras de Virginia Kastrup (2008) ao ato de inventar corresponde a criação de problemas em torno das experiências vividas: a aprendizagem inventiva promove rupturas e nos incita a pensar alternativas diversificadas. Além disso, nos estimula a perceber valores estéticos em elementos que em outros contextos talvez fossem impossíveis. 
É importante destacar que o desenho, como reflexão visual, não está ligado à imagem figurativa, mas abarca formas de representação visual de um pensamento, isto é, estamos falando de diagramas, em termos bastante amplos, como desenhos de um pensamento, uma concepção visual ou um pensamento esboçado. Não é um mapa do que foi encontrado, mas um mapa confeccionado para encontrar alguma coisa. $E$ os encontros, normalmente acontecem em meio a buscas intensas. Os desenhos, desse modo, são formas de visualização de uma possível organização de ideias, pois guardam conexões, como por exemplo, hierarquizações, subordinações, coordenações, deslocamentos, oposições e ações mútuas (SALLES, 2007, p. 35).

Durante as práticas educativas com as crianças, investimos no trânsito entre experiências de contato com exposições artísticas como disparadoras ao imbricarmos em um processo de investigação subjetiva das referências que esta experiência poderia ensinar, evocar e sensibilizar-nos. Nossos questionamentos às crianças permeavam àquilo que movimentava seus saberes entorno ao que já sabiam sobre o tema, a que ideias remetiam, que memórias poderiam relacionar com o que era visto (e também ao que não era explicitado), provocando-as a sinalizar o que mais Ihes possibilitava pensar. A partir deste enfoque, nos implicamos a tomar a aprendizagem não centrada na apreensão técnica dos aspectos que constituem a obra em si, muito menos do ponto de vista comunicativo apenas, mas no que ela potencializa, naquilo que produz nos/com os sujeitos que por ele são interpelados.

O desenho como registro, como um método de construir mapas mentais de nossas ideias, criar e difundir imaginários essencialmente visuais, pode ser compreendido também como um dos aspectos que envolvem nosso desenvolvimento cognitivo e cultural: já na infância somos apresentados às narrativas gráficas. Construímos nossas referências, formas de compreender e representar o universo simbólico à nossa volta. É recorrente nas representações pueris, por exemplo, alusões àquilo que é visualizado no entorno: desenhos animados povoados por heróis e princesas, emergem a todo momento, pois é neste período que começamos a compreender como se desenvolvem as narrativas, bem como, seus códigos temporais, linguísticos e comunicativos, próprios da cultura midiática contemporânea.

No que tange à produção contemporânea em arte, temos presenciado que é crescente a busca por elementos que potencializem processos de interação e construção de significados, uma vez que nem sempre estamos familiarizados com uma produção que permeia o inusitado, o diferente. É comum nos depararmos com discursos ainda modernos e/ou tradicionais que impedem ou dificultam aproximações com a produção atual no campo das artes visuais, sobretudo em ambientes de educação formal. Isso decorre de inúmeros

Revista Digital do LAV - Santa Maria - vol. 12, n. 1, p. 82 - 95 - jan./abr. 2019 ISSN 1983 - 7348 http://dx.doi.org/10.5902/1983734837258 
fatores, dentre os quais, destacamos a carência de experiências estéticas desvinculadas do simples fazer como destreza técnica; da mesma forma, pela falta de espaços expositivos que propiciem vivências significativas no campo das artes, assim como políticas públicas locais de fomento e disponibilização à comunidade.

Tendo em vista que muitas produções artísticas contemporâneas estão dotadas de determinadas especificidades (oriundas de sua natureza visual/afetiva) nos colocamos a pensar que as experiências estéticas não poderiam ser conjecturadas dentro de uma estrutura formal, semelhante à visitação de um museu no formato "cubo branco". Ao contrário, necessitaríamos um dinamismo experimental, por vezes intuitivas ao alcance de todos. Pois, os atravessamentos que estes processos colaborativos estabeleceram com os sujeitos constitui-se potencia edu(vo)cativa, repleta de elementos oriundos de imaginários coletivos os quais ancoramos nossas percepções e significação previamente apreendida, desde concepções íntimas, a imaginários coletivos produzidos pela cultura.

Diante dos excessos de imagens (e artefatos produzidos pela cultura), ressalta-se a importância de adotar posturas experimentais e inventivas frente às práticas educativas, almejamos ampliar as possibilidades de elaboração entorno das produções visuais contemporâneas, pois, nos ambientes educativos institucionalizados "existe a necessidade de que a sala de aula de arte seja um lugar de produção crítica cultural, um lugar no qual o visual seja produzido, à maneira como o fazem os artistas contemporâneos - mediante assemblage, bricolagem, instalação, performance, montagem" (HERNÁNDEZ, 2007, p. 64).

Explorar a potência edu(vo)cativa das artes nos impele a pensar o conhecimento e ativismo no espaço educativo, pois favorece processos criativos e investigativos a partir de proposições inter/multi/transdisciplinares. O fator que mobilizou nosso processo decorre da necessidade da integração de áreas do conhecimento que atualmente se concebem fragmentadas, bem como, o desejo em implementar processos colaborativos de aprendizagem que articulem saberes distintos. 


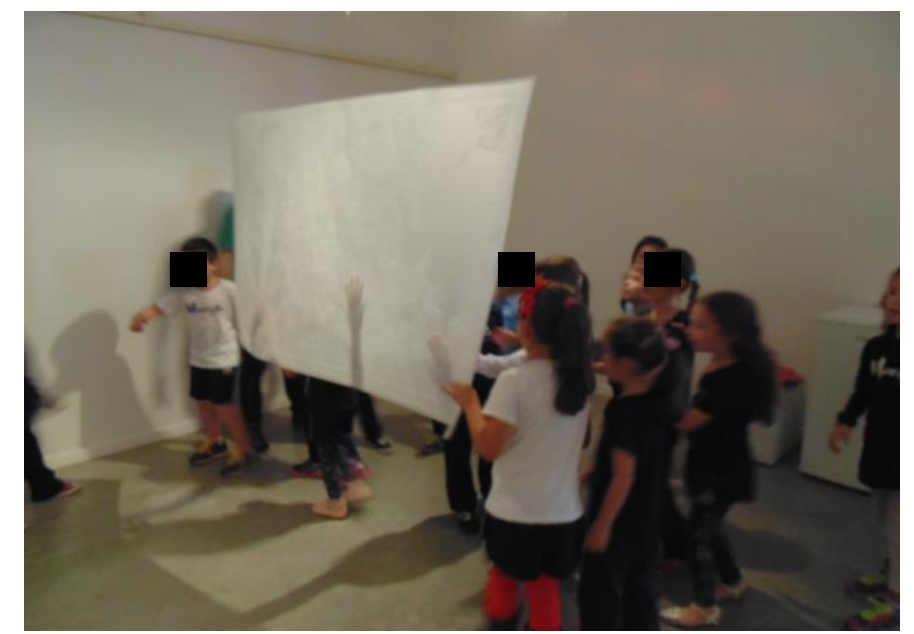

Figura 03. Crianças durante visita à exposição "A Translucidez do Corpo". Santa Maria, RS, 2017.

Fonte: Arquivo Pessoal.

Durante as proposições, almejamos o protagonismo infantil, a fala espontânea, o movimento dialógico, endossados pelas vivencias, percepções e conexões subjetivas atrelados à experiência coletiva. Ao desenvolvermos projetos educativos nestes espaços expositivos (institucionalizados ou não), propusemos estratégias pautadas por etapas: conhecimentos prévios (saberes dos sujeitos), contato visual, contato tátil com os materiais, encontro com artista, interações com as obras, realização de oficinas e avaliação do processo e das elaborações. Sendo as duas últimas etapas aquelas que mais nos detivemos a problematizar o que seriam desdobramentos de uma abordagem "edu(vo)cativa". Apesar de estarmos atentos durante todo o processo, era ao final da proposição que podíamos perceber com maior ênfase - a partir de suas percepções espontâneas - o que aquele compilado de artefatos mobilizava sob os distintos modos de pensar a imagem inventada e as particularidades de cada sujeito.

Ao examinar as relações dos sujeitos envolvidos com as exposições itinerantes - seus diálogos, interpretações e reconstruções - percebeu-se que a negociação é fundamental para desenvolver e estimular a construção do conhecimento a partir de uma abordagem educativa política, crítica, que potencializa o caráter subjetivo e colaborativo com/entre os sujeitos. Diante da experiência de aprender com/a partir das artes, estamos lidando com imprevisibilidades, incongruências, insatisfação e a constante possibilidade de revermos nossas concepções e demais processos constitutivos.

\section{Opacidade e transparência: questões de (in)visibilidades em educação}

As experimentações realizadas sinalizam o potencial da arte nos processos educativos, demonstrando sua relevância ao provocar o pensamento em relação ao que está dado 
como normativo - o que não é nenhuma novidade. Igualmente, não é novo dizer que promove articulações antes impensadas, pois impele o pensamento a ancorar novas/outras novas experimentações, possibilitando-nos perceber a necessidade da exploração material, da diversidade de práticas que promovam a busca por soluções deslocadas do senso comum. Há uma grande tendência a recorrer às imagens, conceitos e ideias já prontas, aludindo a imaginários coletivos oriundos de campos da publicidade, narrativas cinematográficas, produtos e desejos criados e veiculados pela indústria cultural (personagens presentes nos acessórios escolares - cadernos, estojos, mochilas). Sob estes aspectos, talvez tenhamos configurado nosso principal desafio: estimular processos criativos independentes e inventivos destituídos das representações apreendidas de outros contextos, especialmente ao propor relações entre os inúmeros artefatos que atravessam nossas experiências visuais cotidianas.

Os elementos de negociação entre os diversos saberes oriundos da experiência, da vida vivida com o âmbito acadêmico oriundo do campo teórico, das reflexões construídas nos ambientes educativos e de socialização de saberes, são, também, parte de uma estrutura que é narrativa, que perpassa tramas, tessituras, movimentos de ida e volta, de relação entre partes distintas, mas que em algum momento se encontram. Durante cada vivência, nos percebemos implicados com o universo das distintas perspectivas, das relações entre saberes - individuais e coletivos - além dos imaginários criados pela grande mídia, percepções advindas dos núcleos familiares, pequenos círculos de convivência social, etc.; motores de propulsão no espaço de aprendizagem.

Aprendemos através do ato de estabelecer relações - o conhecimento não está em si mesmo, mas naquilo que é produzido a partir das conexões, dos diálogos estabelecidos (GERGEN, 1996). É importante pensarmos que todos os métodos são invenções, foram criados e legitimados a partir de critérios específicos. Ter em conta a natureza exploratória do processo investigativo - relação com a perspectiva enfocada pelo bricoleur, por exemplo, que nas palavras de Kincheloe e Barry (2004), implica reconhecer que há uma multiplicidade de caminhos de natureza relacional com os quais podemos fazer uso durante um processo de aprender - nos permite experimentar, inventar.

O que estas experiências nos têm movimentado - como artistas e professores de artes visuais? Talvez, aguçado com vivacidade nossa curiosidade infantil: uma curiosidade sincera, ingênua, realmente interessada e livre de preconceitos, disposta a arriscar-se. Além disso, a estarmos atentos e atentas aos diversos saberes oriundos da experiência, da vida vivida da comunidade em diálogo com o campo acadêmico oriundo do campo teórico, das reflexões construídas nos ambientes educativos e de socialização. 
Pensar qual o sentido deste tema/processo incita perceber que 0 ato de aprender pode surgir a partir de um desconforto, da sensação de que algo permanece fora do foco do olhar e que poderia ser revisto, revisitado, desvelado ou reorganizado. Talvez, tecer possibilidades - construir mapas - mapas visuais onde se relacionam não apenas das diferentes formas, espaços, linhas, planos, mas onde começamos a estabelecer relações, conectamos ideias/argumentos e (re)configuramos nossas percepções de mundo. Assim, levando-nos a acreditar que estas ações educativas, abordagens práticas, críticas e criativas entorno da arte e suas potencialidades edu(vo)cativas, continuam reverberando significativas e instigantes possibilidades de ação, bem como, resinifica nossas próprias práticas e formas de atuar nestes espaços.

\section{Referências}

CUNHA, S.V. da. Uma arte do nosso tempo para as crianças de hoje. In: CUNHA, S. R.V; CARVALHO, R.S. (Org.). Arte contemporânea e educação infantil: crianças observando, descobrindo e criando. Porto Alegre: Mediação, 2017.

DALLA VALLE, L. Cultura visual y entornos edu(vo)cautivos: la potencia del arte como estrategia pedagógica en educación primaria. In: APRAIZ, E. A; ARRIAGA, A.A; BARAZE, I. M. (Org.). Arte, Ilustración y cultura visual: diálogos en torno a la mediación educativa crítica dentro y fuera de la escuela. País Vasco: Editorial del País Vasco, 2018.

GERGEN, K. Realidades y relaciones: aproximaciones a la construcción social. España: Paidós,1996.

HERNÁNDEZ, F. Catadores da Cultura Visual: uma proposta para uma nova narrativa educacional. Porto Alegre: Mediação, 2007.

KAStruP, V.; Tedesco, S.; PASSOS, E. Políticas da Cognição. Porto Alegre: Sulina, 2008.

KINCHELOE, J. L.; BERRY, K. S. Rigour and complexity in Education Research. Conceptualizing the Bricolage, Open University Press, New York, 2004.

RESENDE, J. In: DERDYK, E. (Org.). Disegno. Desenho. Desígnio. São Paulo: Editora Senac São Paulo, 2007.

SALLES, C. A. In: DERDYK, E. (Org.). Disegno. Desenho. Desígnio. São Paulo: Editora Senac São Paulo, 2007. 
' Doutorado em Artes e Educação (Doctorat Arts i Educació - Universitat de Barcelona/ES, 2012); Mestrado em Artes Visuais e Educação (Màster Universitari en Arts Visuals i Educació: Un Enfocament Construccionista - Universitat de Barcelona/ Universitat de Girona/ Universidad de Granada - Espanha/ 2009); Mestrado em Educação (Linha Educação e Arte) pela Universidade Federal de Santa Maria (CE/PPGE/UFSM/2008); Especialização em Arte e Visualidade pela Universidade Federal de Santa Maria (2005); Licenciatura Plena em Desenho e Plástica (Universidade Federal de Santa Maria/2003); Bacharelado em Desenho e Plástica (Universidade Federal de Santa Maria/2002). É professor adjunto (Dedicação Exclusiva) do Departamento de Artes Visuais/ CAL/UFSM; atua no Programa de Pós-Graduação em Artes Visuais/PPGART/Mestrado - Linha de Pesquisa Arte e Cultura, e no Doutorado, na Linha Arte e Transversalidade (PPGART); nos Cursos de Graduação Bacharelado e Licenciatura em Artes Visuais. Co-orienta no Mestrado e Doutorado em Educação, Linha de Educação e Artes do PPGE/CE/UFSM.

Como citar esse artigo:

VALLE, Lutiere Dalla. A potência edu(vo)cativa da arte contemporânea: desafios e possibilidades. Revista Digital do LAV, Santa Maria: UFSM, v. 12, n. 1, p. 82-95, jan./abr. 2019. 